\title{
Indicadores de desempenho dos Sistemas de Gestão Ambiental (SGA): uma pesquisa teórica
}

\author{
Lucila Maria de Souza Campos UNIVALI \\ Daiane Aparecida de Melo UNIVALI
}

\section{RESUMO}

Este artigo tem por objetivo apresentar os principais tipos de indicadores de desempenho que podem ser utilizados por empresas que possuem um sistema de gestão ambiental (SGA). Neste contexto, o artigo apresenta uma abordagem da gestão ambiental e dos indicadores de medição de desempenho, enfatizando a importância dos indicadores de desempenho ambiental para um SGA e para a organização. Trata-se de uma pesquisa teórica que investigou artigos, teses, dissertações e documentos publicados por empresas que possuem seus SGA certificados. Estes indicadores foram divididos de acordo com os requisitos da norma ISO 14001. Por fim, o artigo inicia uma discussão de como estes indicadores podem tornar-se estratégicos ou parte da estratégia ambiental de uma organização.

PALAVRAS-CHAVE

Indicadores, desempenho, ambiental, Sistema de Gestão Ambiental (SGA).

\section{Performance indicators of Environmental Management System (EMS): a theoretical research}

\begin{abstract}
This paper intends to present the main types of performance indicators that can be used for companies that have an environmental management system (EMS). Is this context, the paper presents an overview about environmental management and performance indicators, emphasizing the importance of environmental indicators for the performance of an EMS and for the organization. This is a theoretical research based on papers, thesis, dissertations and other published documents of companies with EMS certified. The indicators was divided according to the ISO 14001 requirements. Finally, the paper begins a discussion about how these indicators can became strategics or part of an environmental strategic of an organization.
\end{abstract}

\section{KEY WORDS}

Indicators, performance, environmental, Environmental Management System (EMS). 


\section{INTRODUÇÃO}

Nas últimas décadas, o cenário mundial de avanços tecnológicos enfatiza assuntos relacionados à preservação ambiental. A gestão ambiental se tornou uma importante ferramenta de modernização e competitividade para as organizações.

Cada vez mais, o setor produtivo em diferentes países está incorporando em seus custos aqueles relacionados com a questão ambiental, implicando necessidades de mudanças significativas nos padrões de produção, comercialização e consumo. Estas mudanças respondem a normas e dispositivos legais rígidos de controle (nacionais e internacionais), associados a um novo perfil de consumidor. É fundamental que as empresas busquem uma relação harmônica com o meio ambiente, mediante a adoção de práticas de controle sobre: os processos produtivos e o uso de recursos naturais renováveis e não-renováveis (CARTILHA FIESP, 2003).

Nessa direção, emerge a demanda de empresas em busca de um Sistema de Gestão Ambiental (SGA) que possa ser aplicado no gerenciamento e controle das ações das empresas sobre o ambiente. Assim, a implantação de um SGA, mais especificamente o SGA segundo a norma NBR ISO 14001 (a mais difundida mundialmente), faz com que o processo produtivo seja reavaliado continuamente, refletindo na busca por procedimentos, mecanismos e padrões comportamentais menos nocivos ao meio ambiente.

No entanto, a implantação de um SGA não garante o seu gerenciamento por si só. Na concepção de Hronec (1994) as medidas são "sinais vitais" da organização que qualificam e quantificam o modo como as atividades atingem suas metas. As medidas ajudam a empresa a estabelecer o grau de evolução ou estagnação de seus processos, fornecendo informações adequadas para que possam ser tomadas ações preventivas e/ou corretivas em busca das metas e objetivos estabelecidos por ela. Por sua vez, estas informações serão úteis também para a tomada de decisão dos gestores e um melhor alinhamento dos objetivos e metas ambientais às estratégias da organização (CAMPOS, 2001; CAMPOS; SELIG, 2002).

A literatura concernente à mensuração do desempenho destaca que para se conseguir um ambiente de gestão eficaz é imprescindível incorporar um sistema de medidas que assegure o alinhamento das atividades com o objetivo maior da organização. A qualidade da sua tomada de decisão em relação a cada atividade e a sua execução também será influenciada pela existência de um sistema apropriado de medidas (CAMPOS, 2001).

Neste contexto, as empresas que não monitoram um conjunto de indicadores de desempenho ambiental podem não estar gerenciando sua performance, tampouco a performance de seu SGA. Assim, para garantir o sucesso nos resultados visando uma maior competitividade, faz-se necessário que as empresas monitorem continuamente indicadores de desempenho ambiental.

Desta forma, o presente trabalho trata-se de uma pesquisa teórica que tem por objetivo apresentar uma abordagem da gestão ambiental e contextualizá-la no ambiente atual das organizações, onde atualmente emerge uma demanda de certificações de SGA. Em seguida apresenta-se uma abordagem dos indicadores de desempenho ambiental, enfatizando a importância destes para as empresas que desejam melhorar continuamente seu SGA e obter vantagem competitiva no mercado.

\section{GESTÃO AMBIENTAL}

Fiorillo e Rodrigues (1996, p. 25) afirmam que a preocupação mundial com o meio ambiente decorre de um simples fator: proteger o meio ambiente. Em última análise, proteger o meio ambiente significa proteger a própria preservação da espécie humana. Diante disto, a nova consciência ambiental, surgida no bojo das transformações culturais que ocorreram nas décadas de 1960 e 1970, ganhou dimensão e situou o meio ambiente como um dos princípios fundamentais do homem moderno. Nos anos 1980 e 1990, os gastos com proteção ambiental começaram a ser vistos pelas empresas líderes não como custos, mas como investimentos para o futuro e, paradoxalmente, como possível vantagem competitiva. A atitude e a postura dos gestores das organizações em todos os segmentos econômicos nos anos 1990 passaram de defensivas e reativas para ativas e criativas e assim entram na visão estratégica das organizações (CAMPOS, 2001; LOPES, 2004).

Destaca-se aqui que tanto os acidentes ambientais ${ }^{1}$ quanto as conferências internacionais ${ }^{2}$ contribuíram de forma significativa para essa nova consciência ambiental e para o acirramento da pressão da opinião pública e das regulamentações sobre as empresas, emergindo uma maior preocupação das empresas em dar uma atenção especial à questão ambiental.

Após a Conferência das Nações Unidas sobre o Meio Ambiente - Rio-92, o desenvolvimento sustentável ${ }^{3}$ se consolidou como o grande destaque na luta pelas causas ambientais, e para Boog e Bizzo (2003) poderá acontecer de forma cada vez mais eficaz se forem utilizados parâmetros confiáveis para as medições das ações que indicam seu desempenho.

A Agenda 21, fruto dessa Conferência Mundial, define propostas de ações em âmbitos regional e local para alcançar o desejado desenvolvimento sustentável (MMA, 1998). Esta 
necessidade de parâmetros relevantes e confiáveis para a medida do desempenho ambiental pode ser atendida com a NBR ISO 14031, que traz uma série de exemplos de indicadores de desempenho ambiental que podem ser utilizados para avaliar o desempenho ambiental das empresas.

\subsection{Sistemas de Gestão Ambiental}

Segundo Maimon (1996), pesquisas revelam que medidas de gestão ambiental alteram a imagem da empresa para fins institucionais, e estão se constituindo cada vez mais como prioridades em suas etapas futuras de gestão empresarial e de investimentos financeiros nas empresas brasileiras. Exemplos recentes de desastres ecológicos envolvendo a maior empresa do Brasil e uma das maiores do mundo do setor petrolífero, a Petrobras, provocam mudanças de estratégias e de sua alta administração, visando torná-la uma empresa de excelência em gestão ambiental integrada.

\section{$A_{\text {importante ferramenta de modernização }}$ e competitividade para as organizações.}

Lopes (2004) afirma que para utilizar as estratégias ambientais competitivas a partir do uso de normas e certificações em empresas, as organizações poderão optar por um de três níveis de ecogerenciamento: 1) limitar-se à conformidade legal; 2) adotar uma postura proativa, antecipando-se e ultrapassando as regulamentações; ou 3) orientar-se para a sustentabilidade e a responsabilidade socioambiental.

O primeiro nível deveria ser obrigatório, mas muitas vezes é deixado de lado pela falta de fiscalização e punições. $\mathrm{O}$ segundo é limitado por pressupor uma legislação mais exigente e necessitar de pressões de consumidores. Por último, orientar-se para a sustentabilidade e responsabilidade social dependerá da disponibilidade de tecnologias apropriadas, consenso social e novo sistema de valores.

Os principais modelos de Sistemas de Gestão Ambiental que evidenciam a evolução destes são:

- Responsible Care: Programa desenvolvido pela Canadian Chemical Producers Association - CCPA, surgido no Canadá em 1984 e implantado em diversos países a partir de 1985, encontra-se atualmente em mais de 40 países com indústrias químicas.

- Norma Britânica BS 7750: iniciou-se em 1991, e teve sua primeira publicação em junho do mesmo ano com a formação de um comitê técnico no British Standards Institution (BSI).

- EMAS - Eco-Management and Audit Scheme: Sistema
Europeu de Eco-Gestão e Auditorias. Foi adotado pelo Conselho da UE em junho de 1993, e é aberto à participação voluntária das empresas desde abril de 1995.

- NBR ISO 14001: norma do conjunto ISO 14000 que especifica os requisitos de tal sistema de gestão ambiental, tendo sido redigida de forma a aplicar-se a todos os tipos e portes de organizações, não estabelecendo requisitos absolutos para desempenho ambiental.

\section{INDICADORES DE MEDIÇÃO DO DESEMPENHO}

Como definição, um indicador é uma ferramenta que permite a obtenção de informações sobre uma dada realidade, tendo como característica principal poder sintetizar diversas informações, retendo apenas o significado essencial dos aspectos analisados (MITCHELL, 2004).

Para Merico (1997, p. 61) e Hammond et al. (1995, p.1), o termo indicador origina-se do latim indicare, que significa anunciar, tornar público, estimar. Segundo Adriaanse (1993), os indicadores têm como objetivo simplificar, quantificar, analisar e comunicar. Assim, os fenômenos complexos são quantitativos e tornados compreensíveis por vários segmentos da sociedade, através dos indicadores.

Dentro deste contexto, pode-se dizer que os indicadores são ferramentas utilizadas para a organização monitorar determinados processos (geralmente os denominados críticos) quanto ao alcance ou não de uma meta ou padrão mínimo de desempenho estabelecido. Visando correções de possíveis desvios identificados a partir do acompanhamento de dados, busca-se identificação das causas prováveis do não cumprimento de determinada meta e propostas de ação para melhoria do processo. Estes dados ainda fornecem informações importantes para o planejamento e o gerenciamento dos processos, podendo contribuir no processo de tomada de decisão.

Outro fator relevante é a finalidade dos indicadores. Eles servem para medir o grau de sucesso da implantação de uma estratégia em relação ao alcance do objetivo estabelecido. Entretanto, é fundamental que seja observado o fato de que "... um indicador muito complexo ou de difícil mensuração não é adequado, pois o custo para sua obtenção pode inviabilizar a sua operacionalização" (CORAL, 2002, p.159).

Hronec (1994) cita cinco benefícios das medidas de desempenho: i) satisfação dos clientes; ii) monitoramento do processo; iii) e iv) benchmarking de processos e atividades, respectivamente; e, por último, v) a geração de mudanças. Porém, é necessário que as medidas de desempenho estejam corretas para haver a mudança com sucesso. 
Para a FNQ - Prêmio Nacional da Qualidade e Tachizawa (2005), o sistema de medição de desempenho deve ser definido a partir da missão da organização e das estratégias relacionadas com essa missão, por meio da identificação dos fatores críticos de sucesso do seu negócio. Os fatores críticos de sucesso são determinados a partir da missão e da estratégia empresarial; um fator crítico de sucesso é o processo crítico que pode ser alvo de melhorias.

Quanto aos tipos de indicadores, de acordo com Lima (2004, p.13) ocorre uma confusão conceitual a respeito da distinção entre Indicadores Ambientais, Indicadores de Desenvolvimento Sustentável e Indicadores de Desempenho Ambiental. Para o autor, indicadores ambientais traduzem dados relativos a determinado componente ou conjunto de componentes de um ou vários ecossistemas; já os indicadores de desenvolvimento sustentável compreendem informações relativas às várias dimensões da sustentabilidade: dimensões econômica, social, ambiental e institucional; e, por último, os indicadores de desempenho ambiental preocupam-se em refletir os efeitos sobre o meio ambiente dos processos e técnicas adotados para realizar as atividades de uma organização, sendo este o foco de nosso estudo.

\subsection{Indicadores de desempenho ambiental}

Os indicadores de desempenho ambiental visam demonstrar as práticas organizacionais no sentido de minimizar os impactos ao meio ambiente decorrentes de suas atividades. Esses indicadores referem-se ao uso de recursos naturais demonstrados em valores monetários e em valores absolutos de quantidade ou consumo, considerando também as iniciativas de gerenciamento ambiental, os impactos significativos relacionados ao setor da atividade e as respectivas ações de minimização (GASPARINI, 2003).

Em pesquisa realizada por Pacheco (2001), sobre a inserção de indicadores de medição do desempenho para o sistema de gestão ambiental, foi ressaltada a relevância da inserção de indicadores de desempenho relacionados aos objetivos estratégicos, para o alcance do sucesso do SGA da empresa. Para Pacheco, o sistema de medição composto por indicadores de desempenho deve estar relacionado aos fatores críticos de sucesso para o SGA, contribuindo, assim, de forma efetiva para a melhoria do desempenho ambiental, aumentando sua competitividade.

O estabelecimento de indicadores de desempenho ambiental tem sido o foco de atenção de diversos estudos em todo o mundo (ATKINSON; HAMILTON, 1996; IMD,
1996; DITZ; RANGANATHAN, 1997; TYTECA et al. 1997; DEMAJOROVIC; SANCHES, 1999). Spangenberg e Bonniot (1998) e Gasparini (2003) também mostram estudos sobre o estabelecimento destes indicadores. Todos vêm realizando pesquisas e empreendendo ações para o estabelecimento de indicadores eficientes.

Como referência conceitual à seleção de indicadores de desempenho ambiental emerge a norma ISO 14031 - "Gestão Ambiental - avaliação do desempenho ambiental ${ }^{4}$ - diretrizes" (NBR ISO 14031, 2004) que trata especificamente das diretrizes para a avaliação de desempenho ambiental e a adoção de indicadores de desempenho ambiental, a qual lista mais de 100 indicadores ilustrativos.

\section{Dara Hronec (1994), as medidas são "sinais vitais" modo como as atividades atingem suas metas.}

A NBR ISO 14031 descreve duas categorias gerais de indicadores a serem considerados na condução da Avaliação de Desempenho Ambiental: Indicador de Condição Ambiental (ICA) e o Indicador de Desempenho Ambiental (IDA), o qual é classificado em dois tipos: Indicador de desempenho gerencial e operacional.

\subsection{Conjunto dos indicadores de desempenho ambiental gerencial e operacional identificados no "estado da arte"}

Foram investigados indicadores de desempenho gerenciais e operacionais que possam monitorar os SGA de empresas certificadas. Assim, foram pesquisados indicadores de desempenho no estado da arte, chegando-se a um total de aproximadamente 200 indicadores possíveis de serem utilizados pelas empresas, mostrados nos quadros a seguir.

Analisando a norma NBR ISO 14031, percebeu-se que a mesma apresenta tanto exemplos de indicadores de desempenho gerencial como de desempenho operacional. Os indicadores gerenciais estão agrupados nas seguintes seções: implementação de política e programas, conformidade, desempenho financeiro e relações com a comunidade; já os indicadores operacionais foram agrupados pela norma nas seções: materiais, energia, serviços de apoio às operações da organização, instalações físicas e equipamentos, fornecimento e distribuição, produtos, serviços fornecidos pela organização, resíduos e emissões. Assim, nota-se que os indicadores operacionais podem ser apropriados para medir o desempenho ambiental das operações de uma organização, 
podendo ser agrupados com base nas entradas e saídas das instalações físicas e equipamentos da organização.

Os demais exemplos de indicadores foram levantados a partir de cartilhas, artigos, dissertações e teses que tiveram como objetivo analisar indicadores de desempenho ambiental para monitorar os SGAs das empresas. Os indicadores de desempenho ambiental gerencial e operacional foram foram identificados em artigos e um indicador foi identificado a partir de uma dissertação.

Observa-se que os indicadores citados na NBR ISO 14031 e no artigo de Feem e Mattei (1998) são todos relacionais a "números de" ou "grau de". Diferente dos indicadores apresentados por Pacheco (2001) e Demajorovic e Sanches (1999), relacionados a índice, percentual e freqüência. Percebe-se também, que não há um consenso entre os indicadores apresentados por estas fontes, no que concerne a este item de política ambiental. Observa-se, ainda, que estão, de alguma forma, presentes nestes indicadores de desempenho sobre política ambiental preocupações com objetivos e metas,

distribuídos por requisito da norma NBR ISO 14001 com a respectiva fonte, os quais estão ilustrados a seguir. Não foram identificados indicadores apenas para três requisitos da norma: 4.4.4. Documentação; 4.4.5. Controle de documentos, e para o requisito 4.5.4. Controle de registros, já que a utilização de indicadores para estes requisitos é menos relevante.

Para o primeiro requisito "4.2. Política ambiental" foram identificados treze indicadores de desempenho ambiental gerencial, mostrados no Quadro 1 a seguir. Destes, oito foram citados como exemplos de indicadores para Avaliação do Desempenho Ambiental pela NBR ISO 14031, no item implementação da Política e Programas. Quatro indicadores com a comunidade, sindicatos, investimentos financeiros, fornecedores, prestadores de serviços e requisitos ambientais relacionados a descrições de trabalho.

Para o requisito "4.3.2 Requisitos legais e outros" foram identificados quatorze indicadores de desempenho ambiental gerencial, mostrados no Quadro 2. Deste total, quatro indicadores foram encontrados dentro da Cartilha FIESP-CIESP, que identifica indicadores de desempenho ambiental da indústria. A cartilha apresenta exemplos práticos de empresas que já utilizam estes indicadores para gerenciar seu SGA. Cinco indicadores foram identificados a partir de artigos e dois indicadores em dissertação. Na tese de Campos (2001) também foram loca-

Quadro 1: Indicadores identificados no requisito 4.2: Política ambiental.

\begin{tabular}{|c|c|c|}
\hline $\begin{array}{l}\text { Requisito ISO } \\
14001\end{array}$ & $\begin{array}{c}\text { NOME DOS INDICADORES } \\
\text { DE DESEMPENHO GERENCIAL }\end{array}$ & FONTE \\
\hline \multirow[t]{4}{*}{$\begin{array}{l}\text { 4.2 Política } \\
\text { ambiental }\end{array}$} & $\begin{array}{l}\text { № de objetivos e metas atingidos } \\
\text { № de unidades organizacionais atingindo os objetivos e metas ambientais } \\
\text { Grau de implementação de códigos de gestão e práticas de operação } \\
\text { № de iniciativas implementadas para prevenção da poluição } \\
\text { № de níveis gerenciais com responsabilidades ambientais específicas } \\
\text { № de empregados que têm requisitos ambientais em suas descrições de trabalho } \\
\text { № de fornecedores e prestadores de serviço consultados sobre questões ambientais } \\
\text { № de prestadores de serviço contratados com SGA implementado ou certificado }\end{array}$ & $\begin{array}{l}\text { NBR ISO } 14031 \text { (2004) } \\
\text { Política e programas }\end{array}$ \\
\hline & № de fornecedores certificados com a norma ambiental & FEEM e MATTEI (1998) \\
\hline & Índice percentual de clientes satisfeitos com o desempenho ambiental & PACHECO (2001) \\
\hline & $\begin{array}{l}\text { Percentual de atuação em responsabilidade ambiental } \\
\text { Freqüência de relacionamento com o sindicato e com a comunidade vizinha } \\
\text { Percentual de resultado total investido em ações ambientais }\end{array}$ & $\begin{array}{l}\text { DEMAJOROVIC e } \\
\text { SANCHES (1999) }\end{array}$ \\
\hline
\end{tabular}


lizados dois indicadores que podem ser usados para monitorar este requisito da norma. Por fim, foi citado apenas um indicador pela NBR ISO 14031 para este requisito.

No caso deste requisito, há uma série de observações a serem feitas. Primeiro, o fato da NBR ISO 14031 apresentar apenas um indicador, relacionado ao número de multas e penalidades ou custos a elas atribuídos. Isto demonstra uma visão bastante reducionista por parte da norma a respeito deste requisito. Observa-se, ainda, no Quadro 2, que há indicadores que na forma como estão apresentados são de difícil mensuração, como por exemplo: cumprimento da legislação (TOCCHETTO, 2004) e recuperação de danos ambientais (GASPARINI, 2003). Segundo Coral (2002, p.159) “... um indicador muito complexo ou de difícil mensuração não é adequado, pois o custo para sua obtenção pode inviabilizar a sua operacionalização".

Ainda com relação a este requisito de "requisitos legais e outros", nota-se também um certo consenso em torno de indicadores relacionados a multas, infrações ou não conformidades legais, queixas, parâmetros legais, licenças e passivos, ou seja, todos relacionados a aspectos legais. Observa-se ainda uma referência à certificação (no indicador "certificações ambientais obtidas"), um aspecto que não é legal, mas sim normativo.
$\mathrm{Na}$ busca de indicadores para atender o requisito "4.3.3 Objetivos, metas e programas" foram identificados vinte e quatro indicadores de desempenho ambiental gerencial, dos quais treze indicadores estavam listados na NBR ISO 14031 nos itens implementação da política e programas e relacionamento com a comunidade, mostrados no Quadro 3. Três indicadores foram encontrados dentro da Cartilha FIESP-CIESP. Também foram localizados seis indicadores a partir de artigos e dois indicadores em dissertações.

Observa-se, para este requisito, um número bastante elevado de indicadores expressos somente pelo "número de" (41,67\% dos indicadores), sobretudo nos indicadores apresentados pela NBR ISO 14031. Estes indicadores podem não ser representativos, pois não estariam expressos em percentuais ou índices. Os cinco indicadores apresentados por Bergamini (1999) e Pacheco (2001), por sua vez, parecem ser os mais adequados sob o ponto de vista de mensuração e qualidade da informação, pois trabalham com índices, índices percentuais ou total por tonelada produzida. Nota-se, ainda, um consenso em torno de indicadores relacionados a funcionários/empregados e produtos e/ou materiais.

Ao verificar indicadores para monitorar o requisito "4.4.1 Recursos, funções, responsabilidades e autoridades", foram identificados vinte indicadores de desempe-

Quadro 2: Indicadores identificados no requisito 4.3.2: Requisitos Legais e outros.

\begin{tabular}{|c|c|c|}
\hline $\begin{array}{l}\text { Requisito ISO } \\
14001\end{array}$ & $\begin{array}{c}\text { NOME DOS INDICADORES } \\
\text { DE DESEMPENHO GERENCIAL }\end{array}$ & FONTE \\
\hline \multirow{9}{*}{$\begin{array}{l}\text { 4.3.2 Requisitos } \\
\text { legais e outros }\end{array}$} & № de multas e penalidades ou os custos a elas atribuídos & NBR ISO 14031 (2004) \\
\hline & Cumprimento da legislação & TOCCHETTO (2004) \\
\hline & № de queixas relatadas do meio ambiente & FEEM e MATTEI (1998) \\
\hline & $\begin{array}{l}\text { № de não conformidades legais registradas } \\
\text { Parâmetros legais de descarte de efluentes exigidos pela legislação }\end{array}$ & CAMPOS (2001) \\
\hline & $\begin{array}{l}\text { Total de infrações e multas ambientais } \\
\text { Recuperação de danos ambientais }\end{array}$ & GASPARINI (2003) \\
\hline & $\begin{array}{l}\text { Total do passivo ambiental da organização em sua comunidade } \\
\qquad № \text { de multas } \\
\text { № de acidentes ocorridos ao longo da trajetória da empresa }\end{array}$ & $\begin{array}{l}\text { DEMAJOROVIC e } \\
\text { SANCHES (1999) }\end{array}$ \\
\hline & $\begin{array}{l}\text { Extensão de áreas protegidas ou restauradas } \\
\text { Licenças ambientais obtidas }\end{array}$ & $\begin{array}{l}\text { NATURA apud Cartilha } \\
\text { FIESP (2003) }\end{array}$ \\
\hline & Certificações ambientais obtidas & $\begin{array}{c}\text { GRI/MEPI apud Cartilha } \\
\text { FIESP (2003) }\end{array}$ \\
\hline & Extensão de áreas da organização em áreas legalmente protegidas & $\begin{array}{l}\text { NATURA apud Cartilha } \\
\text { FIESP (2003) }\end{array}$ \\
\hline
\end{tabular}

Fonte: Dados da pesquisa. 
nho ambiental gerencial, sendo que dez destes indicadores foram propostos por Gasparini na sua dissertação (GASPARINI, 2003). Seis indicadores estavam listados como exemplos na NBR ISO 14031 no item desempenho financeiro. Foram localizados ainda quatro indicadores em artigos. Todos estes indicadores estão apresentados no Quadro 4, a seguir.

No caso deste requisito, de "Recursos, funções, responsabilidades e autoridades", percebe-se uma grande quantidade de indicadores (85\%) relacionados a aspectos financeiros (investimento, receita, custos, fundos e retorno). O que demonstra uma preponderância do aspecto financeiro, quando se pensa em desempenho ambiental, para este requisito. Nota-se, ainda, a presença de um indicador, apresentado por Gasparini (2003), que pode ser considerado relevante, mas de difícil mensuração, o indicador "desempenho ambiental na cadeia produtiva".

Para monitorar o requisito "4.4.2 Competência, treinamento e conscientização" foram identificados seis indicadores de desempenho ambiental gerencial. Três indicadores estavam listados como exemplos na NBR ISO 14031, no item relações com a comunidade, e três indicadores foram identificados a partir de artigos. Estes indicadores estão apresentados no Quadro 5.

Quadro 3: Indicadores identificados no requisito 4.3.3: Objetivos, metas e programas.

\begin{tabular}{|c|c|c|}
\hline $\begin{array}{l}\text { Requisito ISO } \\
14001\end{array}$ & $\begin{array}{l}\text { NOME DOS INDICADORES } \\
\text { DE DESEMPENHO GERENCIAL }\end{array}$ & FONTE \\
\hline \multirow[t]{7}{*}{$\begin{array}{l}\text { 4.3.3 Objetivos, } \\
\text { metas e } \\
\text { programas }\end{array}$} & $\begin{array}{l}\text { № de empregados que participam em programas ambientais } \\
\text { № de empregados que tenham recebido premiações e reconhecimento em comparação ao } \\
\text { número total de empregados que participaram do programa } \\
\text { № de empregados treinados x número que necessita treinamento } \\
\text { № de pessoas contratadas individuais treinadas } \\
\text { íveis de conhecimentos obtidos pelos participantes de treinamentos } \\
\text { № de sugestões dos empregados para a melhoria ambiental } \\
\text { № de pesquisas com empregados sobre o seu conhecimento das questões } \\
\text { ambientais da organização } \\
\text { № de produtos com plano explícito de “gestão de produtos" } \\
\text { № de produtos projetados para desmontagem, reciclagem ou reutilização } \\
\text { № de produtos com instrução relativa ao uso e disposição final ambientalmente segura }\end{array}$ & $\begin{array}{l}\text { NBR ISO 14031 } \\
\text { (2004) } \\
\text { Implementação da } \\
\text { Política e programas }\end{array}$ \\
\hline & $\begin{array}{l}\text { № de programas educacionais ambientais ou materiais fornecidos à comunidade } \\
\text { Recursos aplicados para apoiar os programas ambientais da comunidade } \\
\text { № de locais com programas de vida selvagem }\end{array}$ & $\begin{array}{l}\text { NBR ISO 14031 } \\
\text { (2004) } \\
\text { Relacionamento com a } \\
\text { comunidade }\end{array}$ \\
\hline & $\begin{array}{l}\text { Participação em programas de proteção ambiental } \\
\text { Investimento em apoio a programas comunitários }\end{array}$ & $\begin{array}{l}\text { DEMAJOROVIC e } \\
\text { SANCHES (1999) }\end{array}$ \\
\hline & № de Tecnologias Limpas & TOCCHETTO (2004) \\
\hline & $\begin{array}{l}\text { Consumo de energia por empregado ou por valor adicionado } \\
\qquad \text { Emissão de } \mathrm{CO}_{2} \text { por tonelada produzida } \\
\text { Total de resíduos por tonelada produzida }\end{array}$ & BERGAMINI (1999) \\
\hline & $\begin{array}{l}\text { Índice percentual de sugestões para o SGA } \\
\text { Índice percentual de Programas de Gestão Ambiental implantados }\end{array}$ & PACHECO (2001) \\
\hline & $\begin{array}{l}\text { Programas, metas e objetivos para a substituição de materiais } \\
\text { Programas, metas e objetivos para transportes relacionados com a organização } \\
\text { Programas, metas e objetivos para a conservação da biodiversidade }\end{array}$ & $\begin{array}{l}\text { NATURA/GRI apud } \\
\text { Cartilha FIESP (2003) }\end{array}$ \\
\hline
\end{tabular}

Fonte: Dados da pesquisa. 
Percebe-se, para este requisito, que há um foco maior em questões relacionadas a treinamento/atividades, pois dos seis indicadores, três deles remetem-se a esta questão.

Com relação ao requisito "4.4.3 Comunicação", também foram selecionados seis indicadores de desempenho ambiental gerencial. Quatro indicadores estavam listados como exemplos na NBR ISO 14031, no item relações com a comunidade, dois indicadores foram obtidos a partir de uma tese e um indicador de um artigo científico. Os indicadores verificados são apresentados no Quadro 6.

Observa-se, neste requisito, preocupação com aspectos ligados à comunidade (presentes em 2 indicadores), a clientes ( 1 indicador) e à mídia ( 1 indicador). Dois dos indicadores (um de Toccheto, 2004 e outro de Campos, 2001) são praticamente iguais. Um dos indicadores da NBR ISO 14031 não deixa claro o que exatamente está medindo, o indicador "número de locais com relatórios ambientais".

Para o requisito "4.4.7. Preparação e resposta a emergências" foram identificados seis indicadores de desempenho ambiental gerencial, mostrados no Quadro 7, a seguir. Destes, quatro foram extraídos de um artigo e dois indicadores foram listados como exemplos de indicadores para Avaliação do Desempenho Ambiental pela NBR ISO 14031, no item Conformidade.

Os indicadores apresentados no Quadro 7, demonstram uma grande preocupação e consenso com questões relacionadas a riscos e emergências. Porém, os indicadores apre-

Quadro 4: Indicadores identificados no requisito 4.4.1: Recursos, funções, responsabilidades e autoridades.

\begin{tabular}{|c|c|c|}
\hline $\begin{array}{l}\text { Requisito ISO } \\
14001\end{array}$ & $\begin{array}{c}\text { NOME DOS INDICADORES } \\
\text { DE DESEMPENHO GERENCIAL }\end{array}$ & FONTE \\
\hline \multirow{4}{*}{$\begin{array}{l}\text { 4.4.1 Recursos, } \\
\text { funções, } \\
\text { responsabilidades, } \\
\text { autoridades }\end{array}$} & Investimentos em equipamentos de controle ambiental & BOOG e BIZZO (2003) \\
\hline & $\begin{array}{l}\text { Investimentos relacionados ao meio ambiente } \\
\text { Percentual do investimento relacionado ao meio ambiente } \\
\text { Gerentes com responsabilidade ambiental }\end{array}$ & $\begin{array}{l}\text { FEEM e MATTEI, } \\
\text { (1998) }\end{array}$ \\
\hline & $\begin{array}{l}\begin{array}{c}\text { Custos (operacional e de capital) que são associados com os aspectos } \\
\text { ambientais de um produto ou processo }\end{array} \\
\text { Retorno sobre o investimento para projetos de melhoria ambiental } \\
\text { Economia obtida através da redução do uso dos recursos, da prevenção } \\
\text { de poluição ou da reciclagem de resíduos. } \\
\text { Receita de vendas atribuíveis a um novo produto ou subproduto projetado } \\
\text { para atender ao desempenho ambiental ou aos objetivos de projeto } \\
\text { Fundo para pesquisas e desenvolvimento aplicados a projetos com significância ambiental } \\
\text { Responsabilidade legal ambiental que pode ter um impacto material } \\
\text { na situação financeira da organização }\end{array}$ & $\begin{array}{l}\text { NBR ISO } 14031 \\
\text { (2004) } \\
\text { Desempenho } \\
\text { financeiro }\end{array}$ \\
\hline & $\begin{array}{l}\text { Investimento em educação e treinamento ambiental } \\
\text { Investimento em projetos e programas de melhoria ambiental } \\
\text { Desempenho ambiental da cadeia produtiva } \\
\text { Investimento em ações compensatórias } \\
\text { Investimento na extração de matérias-primas } \\
\text { Investimento em atualização tecnológica } \\
\text { Investimento em transporte e distribuição } \\
\text { Investimento em consumo } \\
\text { Investimento em reciclagem e reutilização } \\
\text { Investimento em eliminação }\end{array}$ & GASPARINI (2003) \\
\hline
\end{tabular}

Fonte: Dados da pesquisa. 
Campos, L. M. S.; Melo, D. A. Indicadores de desempenho dos Sistemas de Gestão Ambiental (SGA): uma pesquisa teórica. Produção, v. 18, n. 3 , p. $540-555,2008$

sentados por Cunha e Junqueira (2004) não deixam claro de que forma as mensurações serão feitas, relatando apenas os aspectos a serem avaliados.

Ao verificar indicadores para monitorar o requisito " 4.5 .2 Avaliação dos requisitos legais e outros” foram identificados cinco indicadores de desempenho ambiental gerencial, mostrados no quadro a seguir. Dos cinco indicadores, três foram listados como exemplos de indicadores para Avaliação do Desempenho Ambiental pela NBR ISO 14031 no item conformidade e dois foram identificados em artigos.

No caso deste Quadro 8, que contempla os indicadores relacionados a avaliação de requisitos legais, percebe-se

Quadro 5: Indicadores identificados no requisito 4.4.2: Competência, treinamento e conscientização.

\begin{tabular}{|c|c|c|}
\hline $\begin{array}{l}\text { Requisito ISO } \\
14001\end{array}$ & $\begin{array}{l}\text { NOME DOS INDICADORES } \\
\text { DE DESEMPENHO GERENCIAL }\end{array}$ & FONTE \\
\hline \multirow[t]{3}{*}{$\begin{array}{l}\text { 4.4.2 } \\
\text { Competência, } \\
\text { treinamento e } \\
\text { conscientização }\end{array}$} & $\begin{array}{l}\text { Progresso nas atividades de remediação local } \\
\text { № de iniciativas locais de limpeza ou reciclagem, patrocinadas ou auto-implementadas } \\
\text { Índices de aprovação em pesquisas na comunidade }\end{array}$ & $\begin{array}{l}\text { NBR ISO } 14031 \text { (2004) } \\
\text { Relações com a } \\
\text { comunidade }\end{array}$ \\
\hline & Treinamento ambiental & TOCCHETTO (2004) \\
\hline & $\begin{array}{l}\text { Atividades e treinamentos desenvolvidos no campo ambiental } \\
\text { Investimento em atividades para conscientização ambiental }\end{array}$ & $\begin{array}{l}\text { DEMAJOROVIC e } \\
\text { SANCHES (1999) }\end{array}$ \\
\hline
\end{tabular}

Fonte: Dados da pesquisa.

Quadro 6: Indicadores identificados no requisito 4.4.3: Comunicação.

\begin{tabular}{|c|c|c|}
\hline $\begin{array}{l}\text { Requisito ISO } \\
14001\end{array}$ & $\begin{array}{l}\text { NOME DOS INDICADORES } \\
\text { DE DESEMPENHO GERENCIAL }\end{array}$ & FONTE \\
\hline \multirow[t]{3}{*}{$\begin{array}{c}\text { 4.4.3 } \\
\text { Comunicação }\end{array}$} & $\begin{array}{l}\text { № de consultas ou comentários sobre questões relacionadas ao meio ambiente } \\
\text { № de reportagens da imprensa sobre o desempenho ambiental da organização } \\
\text { № de locais com relatórios ambientais }\end{array}$ & $\begin{array}{l}\text { NBR ISO } 14031 \\
\text { (2004) } \\
\text { Relações com a } \\
\text { comunidade }\end{array}$ \\
\hline & № de reclamações da comunidade & TOCCHETTO (2004) \\
\hline & $\begin{array}{l}\text { № de reclamações relacionadas a algum aspecto ambiental feitas pela comunidade } \\
\text { Percentual de reclamações relacionadas a algum fator ambiental, feitas por algum visitante/cliente }\end{array}$ & CAMPOS (2001) \\
\hline
\end{tabular}

Fonte: Dados da pesquisa.

Quadro 7. Indicadores identificados no requisito 4.4.7: Preparação e resposta a emergências.

\begin{tabular}{|c|c|c|}
\hline $\begin{array}{l}\text { Requisito ISO } \\
14001\end{array}$ & $\begin{array}{l}\text { NOME DOS INDICADORES } \\
\text { DE DESEMPENHO GERENCIAL }\end{array}$ & FONTE \\
\hline \multirow[t]{2}{*}{$\begin{array}{l}\text { 4.4.7 Preparação } \\
\text { e resposta a } \\
\text { emergências }\end{array}$} & $\begin{array}{c}\text { № de simulados de emergências realizados } \\
\text { Percentagem de simulados de preparação e respostas a emergências que } \\
\text { demonstraram a prontidão planejada }\end{array}$ & $\begin{array}{l}\text { NBR ISO 14031, (2004) } \\
\text { Conformidade }\end{array}$ \\
\hline & $\begin{array}{l}\text { Planos de ação de emergência } \\
\text { Resposta a emergências } \\
\text { Plano de gerenciamento de riscos } \\
\text { Comunicação de riscos }\end{array}$ & $\begin{array}{c}\text { CUNHA e JUNQUEIRA } \\
(2004)\end{array}$ \\
\hline
\end{tabular}

Fonte: Dados da pesquisa. 
que todos são indicadores de fácil mensuração, portanto adequados para auxiliarem na gestão do desempenho de um SGA.

Ao localizar indicadores para monitorar o requisito "4.5.3 Não conformidade, ação corretiva e ação preventiva" foram identificados apenas três indicadores de desempenho ambiental gerencial, dos quais dois foram encontrados dentro da Cartilha FIESP-CIESP e um na NBR ISO 14031, no item conformidade. Os indicadores verificados são mostrados no Quadro 9.

Nota-se que este requisito possui o menor número de indicadores identificados na literatura pesquisada, apesar de ser um item importante para a gestão do desempenho de um SGA, pois trata das não conformidades e ações corretivas e preventivas do sistema. Dos três indicadores listados, dois tratam do número de ações corretivas (NBR ISO 14031), um do número e tipo de incidências de não cumprimento de padrões (ou seja, conformidades) e um terceiro de número de penalidades. Interessante notar que o primeiro indicador da NATURA/GRI possui aspecto quantitativo além do qualitativo, quando se refere ao tipo de incidência.
Para o requisito "4.3.1. Aspectos ambientais" foram identificados oitenta e quatro indicadores de desempenho ambiental operacional, mostrados no quadro 10. Deste total, uma quantia relevante de indicadores (trinta e sete, ou seja, $44 \%$ do total) foi citada como exemplo pela NBR ISO 14031, nos seguintes itens de controle operacional:

\section{Im sistema de indicadores de desempenho deve ser definido a partir da missão da organização e das estratégias relacionadas com essa missão.}

materiais; energia; serviço de apoio às operações da organização; resíduos e emissões. Outro número relevante de indicadores (vinte e três) foi verificado dentro da Cartilha FIESP-CIESP, a qual identifica indicadores de desempenho ambiental da indústria. Os indicadores deste requisito foram citados pelo GRI $^{5}$ e pelas empresas Natura, MEPI ${ }^{6}$; $\mathrm{MAHLE}^{7}$; que já utilizam os indicadores apresentados. Também foram identificados quatorze indicadores de desempenho operacional em artigos. Por fim, foram verificados ainda doze indicadores de desempenho ambiental a partir de pesquisa em dissertações e teses.

Quadro 8: Indicadores identificados no requisito 4.5.2: Avaliação dos requisitos legais e outros.

\begin{tabular}{|c|c|c|}
\hline $\begin{array}{l}\text { Requisito ISO } \\
14001\end{array}$ & $\begin{array}{l}\text { NOME DOS INDICADORES } \\
\text { DE DESEMPENHO GERENCIAL }\end{array}$ & FONTE \\
\hline \multirow[t]{2}{*}{$\begin{array}{l}\text { 4.5.2 Avaliação } \\
\text { dos requisitos } \\
\text { legais e outros }\end{array}$} & $\begin{array}{c}\text { Tempo para responder ou corrigir os incidentes ambientais } \\
\text { Grau de atendimento a regulamentos } \\
\text { Grau de atendimento dos prestadores de serviço com requisitos e expectativas pela } \\
\text { organização em contratos }\end{array}$ & $\begin{array}{l}\text { NBR ISO } 14031(2004) \\
\quad \text { Conformidade }\end{array}$ \\
\hline & $\begin{array}{l}\text { № de relatórios impressos positivos e negativos das atividades ambientais da companhia } \\
\text { № de iniciativas do meio ambiente externo relatadas para suportar a companhia }\end{array}$ & FEEM e MATTEI (1998) \\
\hline
\end{tabular}

Fonte: Dados da pesquisa.

Quadro 9: Indicadores identificados no requisito 4.5.3: Não Conformidade (NC), Ação Corretiva (AC) e Ação Preventiva (AP).

\begin{tabular}{|c|c|c|}
\hline $\begin{array}{l}\text { Requisito ISO } \\
14001\end{array}$ & $\begin{array}{c}\text { NOME DOS INDICADORES } \\
\text { DE DESEMPENHO GERENCIAL }\end{array}$ & FONTE \\
\hline \multirow{2}{*}{$\begin{array}{c}\text { 4.5.3 Não } \\
\text { Conformidade, } \\
\text { Ação Corretiva } \\
\text { e Ação } \\
\text { Preventiva }\end{array}$} & № de ações corretivas identificadas que foram encerradas ou não & $\begin{array}{c}\text { NBR ISO } 14031 \text { (2004) } \\
\text { Conformidade }\end{array}$ \\
\hline & $\begin{array}{l}\text { № e tipo de incidências de não cumprimento dos padrões nacionais } \\
\text { ou internacionais vigentes } \\
\text { № de penalidades em caso de não conformidade com questões ambientais }\end{array}$ & $\begin{array}{l}\text { NATURA/GRI apud } \\
\text { Cartilha FIESP (2003) }\end{array}$ \\
\hline
\end{tabular}

Fonte: Dados da pesquisa. 
Campos, L. M. S.; Melo, D. A. Indicadores de desempenho dos Sistemas de Gestão Ambiental (SGA): uma pesquisa teórica. Produção, v. 18 , n. 3 , p. $540-555,2008$

Quadro 10: Indicadores identificados no requisito 4.3.1: Aspectos ambientais.

\begin{tabular}{|c|c|c|}
\hline $\begin{array}{l}\text { Requisito ISO } \\
14001\end{array}$ & $\begin{array}{l}\text { NOME DOS INDICADORES } \\
\text { DE DESEMPENHO OPERACIONAL }\end{array}$ & FONTE \\
\hline \multirow[t]{6}{*}{$\begin{array}{l}\text { 4.3.1 Aspectos } \\
\text { Ambientais }\end{array}$} & $\begin{array}{l}\text { Quantidade de materiais usados por unidade de produto } \\
\text { Quantidade de materiais processados, reciclados ou reutilizados } \\
\text { Quantidade de materiais de embalagem descartados ou reutilizados por unidade de produto } \\
\text { Quantidade de outros materiais auxiliares reciclados ou reutilizados } \\
\text { Quantidade de matéria-prima reutilizada no processo de produção } \\
\text { Quantidade de água por unidade de produto } \\
\text { Quantidade de água reutilizada } \\
\text { Quantidade de materiais perigosos usados no processo de produção }\end{array}$ & $\begin{array}{c}\text { NBR ISO } 14031 \\
\text { (2004) } \\
\text { Materiais }\end{array}$ \\
\hline & $\begin{array}{c}\text { Quantidade de energia usada por ano ou por unidade do produto } \\
\text { Quantidade de energia usada por serviço ao cliente } \\
\text { Quantidade de cada tipo de energia usada } \\
\text { Quantidade de energia gerada com subprodutos ou correntes de processo } \\
\text { Quantidade de unidades de energia economizadas devido a programas de conservação de energia }\end{array}$ & $\begin{array}{c}\text { NBR ISO } 14031 \\
\text { (2004) } \\
\text { Energia }\end{array}$ \\
\hline & $\begin{array}{l}\text { Quantidade de resíduos por ano ou por unidade de produto } \\
\text { Quantidade de resíduos perigosos, recicláveis ou reutilizáveis produzidos por ano } \\
\text { Quantidade de resíduos para disposição } \\
\text { Quantidade de resíduos armazenados no local } \\
\text { Quantidade de resíduos contratados por licenças } \\
\text { Quantidade de resíduos convertidos em material reutilizáveis por ano } \\
\text { Quantidade de resíduos perigosos eliminados devido a substituição de material }\end{array}$ & $\begin{array}{c}\text { NBR ISO } 14031 \\
\text { (2004) } \\
\text { Resíduos }\end{array}$ \\
\hline & $\begin{array}{c}\text { Quantidade de emissões específicas por ano } \\
\text { Quantidade de emissões específicas por unidade de produto } \\
\text { Quantidade de energia desperdiçada, liberada para a atmosfera } \\
\text { Quantidade de emissões atmosféricas com potencial depleção da camada ozônio } \\
\text { Quantidade de emissões atmosféricas com potencial de mudança climática global } \\
\text { Quantidade de material específico descarregado por ano } \\
\text { Quantidade de material específico descarregado na água por unidade de produto } \\
\text { Quantidade de material destinado para aterro sanitário por unidade de produto } \\
\text { Quantidade de energia desperdiçada liberada para a água } \\
\text { Quantidade de efluentes por serviço ou cliente } \\
\text { Ruído medido em determinado local } \\
\text { Quantidade de radiação liberada } \\
\text { Quantidade de calor, vibração ou luz emitida }\end{array}$ & $\begin{array}{c}\text { NBR ISO } 14031 \\
\text { (2004) } \\
\text { Emissões }\end{array}$ \\
\hline & $\begin{array}{l}\text { Quantidade de materiais perigosos usados por prestadores de serviços contratados } \\
\text { Quantidade de produtos de limpeza usados por prestadores de serviços contratados } \\
\text { Quantidade de materiais recicláveis e reutilizáveis usados pelos prestadores de serviços contratados } \\
\text { Quantidade ou tipo de resíduos gerados pelos prestadores de serviços contratados }\end{array}$ & $\begin{array}{l}\text { NBR ISO } 14031 \\
\quad(2004) \\
\text { Serviço de apoio } \\
\text { às operações da } \\
\text { organização }\end{array}$ \\
\hline & $\begin{array}{l}\text { Massa mensal de resíduos da classe I, II e III gerados } \\
\text { Massa mensal de resíduos reciclados em tonelada por tonelada de perfis produz }\end{array}$ & CUNHA (2001) \\
\hline
\end{tabular}


Campos, L. M. S.; Melo, D. A. Indicadores de desempenho dos Sistemas de Gestão Ambiental (SGA): uma pesquisa teórica. Produção, v. 18 , n. 3, p. 540-555, 2008

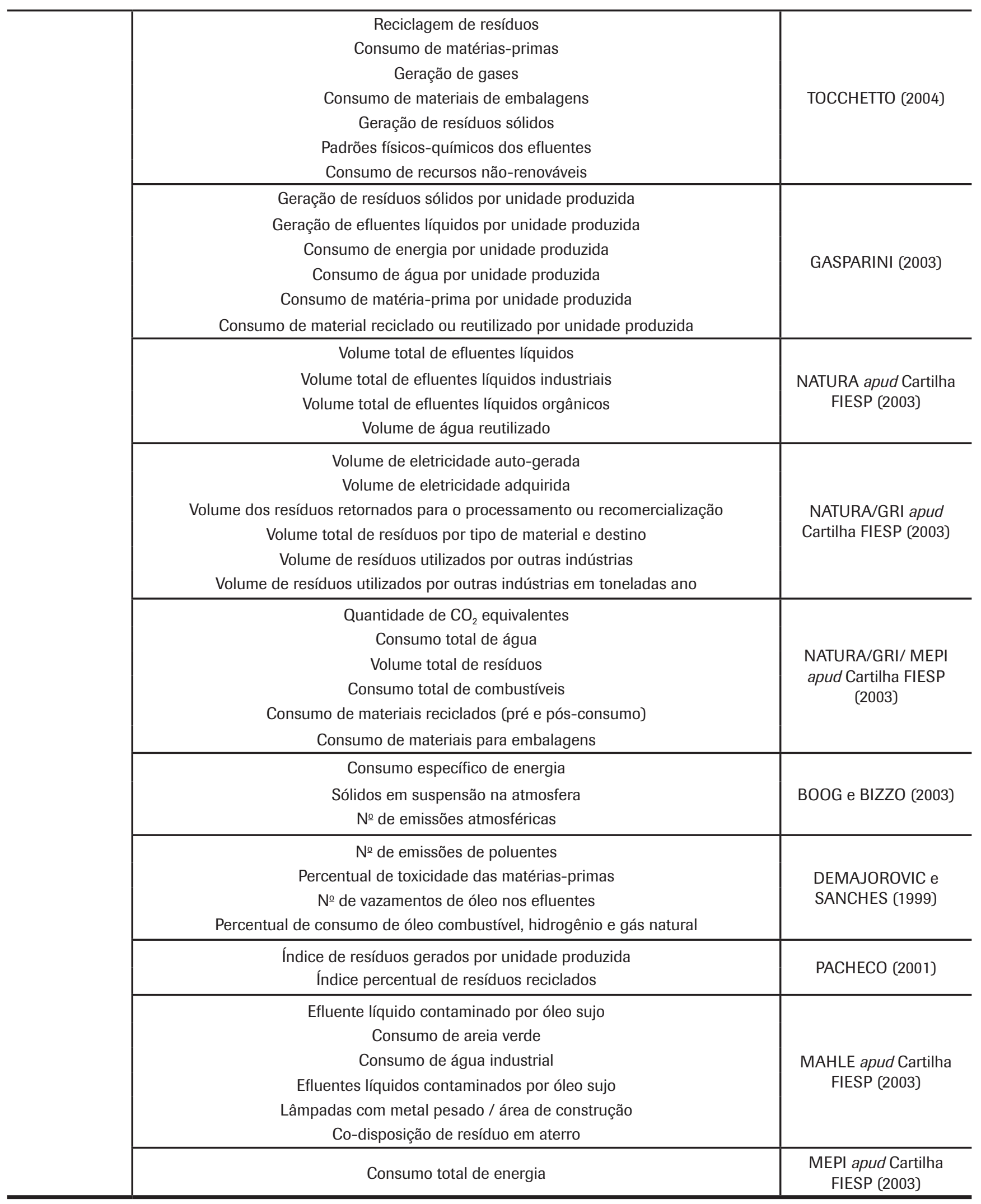


Analisando os indicadores do Quadro 10, percebe-se que todos eles estão associados a aspectos ambientais, como: materiais utilizados, energia, água, matéria-prima, materiais perigosos, resíduos, emissões atmosféricas, efluente, radiação, geração de calor, entre outros. Observase também que, neste requisito, os indicadores da NBR 14031 são de alguma forma repetidos nos demais trabalhos e representam uma coletânea bastante abrangente de indicadores.

Para o requisito "4.4.6. Controle operacional" foram identificados vinte e dois indicadores de desempenho ambiental operacional, mostrados no Quadro 11. Destes, a maioria (treze) foi citada como exemplo pela NBR ISO 14031. Também foram identificados seis indicadores de desempenho operacional em artigos. Por fim, foram localizados outros três na tese de Campos (2001).

Através dos indicadores apresentados no Quadro 11, nota-se que os indicadores da NBR ISO 14031 também são abrangentes e que os demais indicadores, obtidos através de artigos e teses, assemelham-se aos indicadores do Quadro 10 , que representam os aspectos ambientais.

E, para o último requisito verificado "4.5.1. Monitoramento e medição" foram identificados vinte indicadores de desempenho ambiental operacional, mostrados no Quadro 12 , a seguir. Destes, a maioria também foi citada como exemplo pela NBR ISO 14031.

No caso destes indicadores, observa-se certa semelhança entre os mesmos e alguns indicadores apresentados em requisitos anteriores, como os requisitos de controle operacional e aspectos ambientais.

Quadro 11: Indicadores identificados no requisito 4.4.6: Controle operacional.

\begin{tabular}{|c|c|c|}
\hline $\begin{array}{l}\text { Requisito } \\
\text { ISO } 14001\end{array}$ & $\begin{array}{c}\text { NOME DOS INDICADORES } \\
\text { DE DESEMPENHO OPERACIONAL }\end{array}$ & FONTE \\
\hline \multirow[t]{6}{*}{$\begin{array}{c}4.4 .6 \\
\text { Controle } \\
\text { operacional }\end{array}$} & $\begin{array}{l}\text { № de partes de equipamentos com peças projetadas para fácil desmontagem, reciclagem e reutilização } \\
\text { № de horas por ano que uma peça específica do equipamento está em operação } \\
\text { № de situações de emergência (por exemplo: explosões) ou operações não rotineiras (por exemplo: } \\
\text { paradas operacionais) por ano } \\
\text { Área total de solo usada para fins de produção } \\
\text { Área de solo usada para produzir uma unidade de energia } \\
\text { Consumo médio de combustível da frota de veículos } \\
\text { № de veículos da frota com tecnologia para redução da poluição } \\
\text { № de horas de manutenção preventiva dos equipamentos/ano }\end{array}$ & $\begin{array}{c}\text { NBR ISO } 14031 \\
\text { (2004) } \\
\text { Instalações } \\
\text { físicas e } \\
\text { equipamentos }\end{array}$ \\
\hline & $\begin{array}{l}\text { Consumo médio de combustível da frota de veículos } \\
\text { № de carregamentos expedidos por meio de transporte por dia } \\
\text { № de veículos da frota com tecnologia para redução da poluição } \\
\mathrm{N}^{\circ} \text {. de viagens a negócios por modo de transporte } \\
\mathrm{N}^{0} \text {. de viagens de negócios economizadas em decorrência de outros meios de comunicação }\end{array}$ & $\begin{array}{l}\text { NBR ISO } 14031 \\
\quad \text { (2004) } \\
\text { Fornecimento e } \\
\text { distribuição }\end{array}$ \\
\hline & $\begin{array}{l}\text { Consumo de água mensal por pessoa } \\
\text { Consumo de energia elétrica por pessoa } \\
\text { Percentual de resíduos gerados }\end{array}$ & CAMPOS (2001) \\
\hline & $\begin{array}{l}\text { Percentual de emissão de } \mathrm{CO}_{2} \text { por unidade de produto produzido } \\
\text { Percentual de resíduos produzidos por recurso utilizado }\end{array}$ & $\begin{array}{l}\text { BERGAMINI } \\
\text { (1999) }\end{array}$ \\
\hline & Consumo específico de água e Recirculação da água & $\begin{array}{l}\text { BOOG e BIZZO } \\
\text { (2003) }\end{array}$ \\
\hline & $\begin{array}{c}\text { Riscos associados aos processos produtivos e de consumo } \\
\text { Produtos finais gerados na empresa que apresentam algum grau de toxicidade e risco } \\
\text { Produtos de maior risco }\end{array}$ & $\begin{array}{l}\text { DEMAJOROVIC } \\
\text { e SANCHES } \\
\text { (1999) }\end{array}$ \\
\hline
\end{tabular}




\section{CONSIDERAÇÕES FINAIS}

Analisando os cerca de 200 indicadores apresentados nos 12 Quadros, observa-se, em linhas gerais, um conjunto de indicadores interessante e abrangente tanto para aspectos relacionados ao desempenho operacional quanto para o desempenho gerencial. Porém, observa-se também que alguns indicadores são vagos, ou de difícil mensuração. Muitos, ainda, apesar de fontes diferentes, traduzem condições semelhantes, e outros, podem ser considerados redundantes nas classificações apresentadas, como por exemplo, os indicadores apresentados para os requisitos de "controle ambiental", "aspectos ambientais" e "monitoramento e medição", respectivamente, Quadros 10, 11 e 12.

Alguns indicadores, como destacamos nas observações dos requisitos "política ambiental" e "objetivos, metas e programas" (respectivamente quadros 1 e 3), referem-se apenas a "números de", ou seja, são indicadores absolutos, que não expressam uma comparação ou uma razão, e, portanto, podem não estar apresentando informações consistentes. Indicadores medidos através de porcentagens ou índices, por exemplo, podem ser considerados mais adequados para avaliar o desempenho, pois expressam algum tipo de relação.

Quanto aos indicadores de desempenho ambiental identificados no estado da arte, é importante salientar que estes não se limitam aos exemplos identificados, e convém que não sejam entendidos como necessários nem mesmo apropriados para todas as organizações. Como sugere a própria norma NBR ISO 14031 (2004), as organizações, suas políticas, objetivos e estruturas variam muito. Assim, cada organização deve selecionar indicadores que reconheça como importantes para definir seus critérios de desempenho ambiental.

Mas como estes indicadores podem ser estratégicos ou parte da estratégia ambiental de uma organização? Uma das alternativas é definir os indicadores de desempenho ambiental alinhando-os à política, aos objetivos e as metas

Quadro 12: Indicadores identificados no requisito 4.5.1: Monitoramento e medição.

\begin{tabular}{|c|c|c|}
\hline $\begin{array}{c}\text { Requisito ISO } \\
14001\end{array}$ & $\begin{array}{c}\text { NOME DOS INDICADORES } \\
\text { DE DESEMPENHO OPERACIONAL }\end{array}$ & FONTE \\
\hline \multirow[t]{4}{*}{$\begin{array}{c}4.5 .1 \\
\text { Monitoramento } \\
\text { e Medição }\end{array}$} & $\begin{array}{l}\text { № de produtos introduzidos no mercado com propriedades perigosas reduzidas } \\
\text { № de produtos que podem ser reutilizados ou reciclados } \\
\text { Percentagem do conteúdo de um produto que pode ser reutilizado ou reciclado } \\
\text { Índice de produtos defeituosos } \\
\text { № de unidades de subprodutos gerados por unidade de produto } \\
\text { № de unidades de energia consumidas durante uso do produto } \\
\text { Duração do uso do produto } \\
\text { № de produtos com instrução referente ao uso e à disposição ambientalmente seguros }\end{array}$ & $\begin{array}{l}\text { NBR ISO } 14031 \\
\text { (2004) } \\
\text { Produtos }\end{array}$ \\
\hline & $\begin{array}{c}\text { Quantidade de agentes de limpeza usados por metro quadrado } \\
\text { Quantidade de combustível consumido } \\
\text { Quantidade de licenças vendidas de processos melhorados } \\
\text { № de casos de incidentes de riscos de crédito ou insolvências relacionados a questões } \\
\text { ambientais (organizações financeiras) } \\
\text { Quantidade de materiais usados durante os serviços de pós-venda dos produtos }\end{array}$ & $\begin{array}{l}\text { NBR ISO } 14031 \\
\text { (2004) } \\
\text { Serviços fornecidos } \\
\text { pela organização }\end{array}$ \\
\hline & $\begin{array}{c}\text { Total de energia elétrica } \\
\text { Volume de água consumido }\end{array}$ & CUNHA (2001) \\
\hline & $\begin{array}{c}\text { Investimento em gás natural } \\
\text { Geração de energia elétrica na própria organização } \\
\text { Co-geração de vapor e energia elétrica por meio de combustão de gás natural } \\
\text { Investimentos em fontes de energia mais eficientes } \\
\text { Redução de emissão de poluentes gasosos e líquidos }\end{array}$ & $\begin{array}{l}\text { DEMAJOROVIC e } \\
\text { SANCHES (1999) }\end{array}$ \\
\hline
\end{tabular}

Fonte: Dados da pesquisa. 
da organização. Desta forma, ter um sistema de indicadores de desempenho pode ser fundamental para melhorar a eficiência e eficácia do SGA da empresa, no entanto, faz-se necessário que a empresa tenha claro sua missão, estratégias e fatores críticos de sucesso para definição e uso freqüente destes indicadores.

\section{NOTAS}

1. Como os que ocorreram nas décadas de 1970 e 80: Chernobyl na União Soviética; Seveso na Itália; Bhopal na Índia e Basiléia na Suíça. No Brasil, pode-se destacar: o vazamento de um oleoduto em Vila Socó, Cubatão-SP; o descarrilamento e vazamento de um trem carregado de combustível na Bahia; o vazamento de um reservatório de uma indústria petroquímica no Rio de Janeiro; o derrame de cerca de 1,3 mil toneladas de óleo na Baía de Guanabara-RJ em 2000; e o afundamento de uma balsa que despejou 1,8 milhão de litros de óleo em Barbacena-PA (VATIMBELLA, 1992; VALLE, 1995; ALBERTON, 2003).

2. Dentre as principais destacam-se: a Conferência das Nações Unidas sobre o Meio Ambiente em Estocolmo (1972), a Convenção sobre Comércio Internacional de Espécies da Flora e Fauna ameaçadas de extinção (1975), o Protocolo de Montreal (1987), a Rio ECO-92 (1992) e o Protocolo de Kyoto (1997).

3. O conceito de Desenvolvimento Sustentável mais difundido diz que desenvolvimento sustentável é "aquele que atende às necessidades do presente sem comprometer a possibilidade de gerações futuras atenderem às suas próprias necessidades" (CMMAD, 1988, p. 46).

4. Segundo esta norma, a avaliação do desempenho ambiental é, ao mesmo tempo, um processo e uma ferramenta de gestão interna, planejada para prover o gerenciamento com informações confiáveis e verificáveis, em base contínua, visando determinar se o desempenho ambiental de uma organização está adequado aos critérios estabelecidos pela administração da organização. A norma é aplicável a todas as organizações, independentemente do tipo, tamanho, localização e complexidade (NBR ISO 14031, 2004).

5. GRI - Global Reporting Initiative

6. MEPI - Measuring the Environmental Performance of Industry

7. MAHLE - Fábrica da MAHLE unidade Mogi-Guaçu

\section{Artigo recebido em 26/03/2007 Aprovado para publicação em 03/06/2008}

\section{REFERÊNCIAS}

ADRIAANSE, A. Environmental policy performance indicators. General of Environment of the Dutch Ministry of Housing, VROM, The Hague, 1993.

ALBERTON, A. Meio Ambiente e Desempenho Econômico - Financeiro: Impacto da ISO 14001 nas Empresas Brasileiras. 2003. 285 f. Tese - Engenharia de Produção e Sistemas, Universidade Federal de Santa Catarina, Florianópolis, 2003.

ASSOCIAÇÃO BRASILEIRA DE NORMAS TÉCNICAS. NBR ISO 14031: Gestão Ambiental Avaliação de Desempenho Ambiental - diretrizes. Rio de Janeiro, 2004.

ATKINSON, G.; HAMILTON, K. Accounting for Progress: Indicator for Sustainable Development. Environment, September 1996.
BERGAMINI, Jr. S. Contabilidade e riscos ambientais. Revista do BNDES - Banco Nacional de Desenvolvimento Econômico e Social. Rio de Janeiro: n.11, jun.1999.

BOOG, E. G.; BIZZO, W. A. Utilização de indicadores ambientais como instrumento para gestão de desempenho ambiental em empresas certificadas com a ISO 14001. In: X SIMPÓSIO DE ENGENHARIA DA PRODUÇÃO - SIMPEP, 2003, Bauru. Anais do X SIMPEP - Simpósio de Engenharia da Produção, 2003.

CAMPOS, L. M. de S. SGADA - Sistema de Gestão e Avaliação de Desempenho Ambiental: uma Proposta de Implementação. 2001. 220 f. Tese - Engenharia de Produção e Sistemas, Universidade Federal de Santa Catarina, Florianópolis, 2001.

CAMPOS, L. M. de S.; SELIG, P. M. SGADA Sistema de Gestão e Avaliação de Desempenho
Ambiental: A Avaliação de um Modelo de SGA que utiliza o Balanced Scorecard (BSC). REAd - Revista Eletrônica de Administração, Edição Especial 30, v. 8, n. 6, p. 139-163, 2002.

CARTILHA FIESP-CIESP. Indicadores de desempenho ambiental da indústria. 2003. Disponível em: http://www.fiesp.com.br/ download/publicacoes_meio_ambiente/ cartilha_indic_ambiental.pdf. Acesso em: 13 de fevereiro 2006.

CMMAD - Comissão Mundial de Meio Ambiente e Desenvolvimento. Nosso Futuro Comum. Rio de Janeiro: FGV, 1988.

CORAL, E. Modelo de planejamento estratégico para a sustentabilidade empresarial. 2002. 275 f. Tese - Engenharia da Produção e Sistemas, Universidade Federal de Santa Catarina, Florianópolis, 2002. 
CUNHA, R. S. Avaliação do desempenho ambiental de uma indústria de processamento de alumínio. 2001. 100 f. Dissertação - Engenharia de Produção e Sistemas, Universidade Federal de Santa Catarina, Florianópolis, 2001.

CUNHA, I.; JUNQUEIRA, L. P. Gestão da Sustentabilidade: Risco ambiental e Conflito, Governança e Cooperação. Anais do XXVIII Encontro Nacional dos Programas de Pósgraduação em Administração - ENANPAD, Curitiba, 2004.

DEMAJOROVIC, J.; SANCHES, C. S. Aprendizado e indicadores ambientais: perspectivas para as organizações. Anais do XXII Encontro Nacional dos Programas de Pósgraduação em Administração - ENANPAD, Foz do Iguaçu, 1999.

DITZ, D.; RANGANATHAN, J. Measuring Up: Toward a Common Framework for Tracking Corporate Environmental Performance. Washington, DC: World Resources Institute, 1997.

FEEM, A. M.; MATTEI, F. E. E. Environmental Indicators in EMAS Environmental Statements. Milano, Italy, 1998. Disponível em: http://www. feem.it/NR/rdonlyres/A5249CBD-6BE6-4F18AFBB-9886E967EF14/510/2698.pdf. Acesso em 21 de março 2006.

FIORILLO, C. A. P.; RODRIGUES, M. A. Direito Ambiental e Patrimônio Genético. Belo Horizonte: Del Rey, 1996.

GASPARINI, L. V. L. Análise das inter-relações de indicadores econômicos, ambientais e sociais para o desenvolvimento sustentável. 2003. 221 f. Dissertação - Engenharia de Produção e Sistemas, Universidade Federal de Santa Catarina, Florianópolis, 2003.
HAMMOND, A.; ADRIAANSE, A.; RODENBURG, E.; BRYANT, D.; WOODWARD, R. Environmental indicators: a systematic approach to measuring and reporting on environmental policy performance in the context of sustainable development. Baltimore: World Resources Institute Publications, 302p., 1995.

HRONEC, S. M. Sinais Vitais. São Paulo: Makron Books, 1994.

IMD - Managing the Industrial and Business Environment: Environmental Performance Indicators. Lausanne, International Institute for Management Development, IMD - MIBE Working Paper, 1996.

LIMA, L. H. Contabilidade ambiental - avanços internacionais e atraso no Brasil. Anais do I Congresso Acadêmico sobre o Meio Ambiente e Desenvolvimento Sustentável do Rio de Janeiro, FGV, Rio de Janeiro, 2004.

LOPES, J. R. M. Sistema de gestão ambiental integrada - SGAI: uma análise econômica estrutural. Anais do I Congresso Acadêmico sobre o Meio Ambiente e Desenvolvimento Sustentável do Rio de Janeiro, FGV, Rio de Janeiro, 2004.

MAIMON, D. Passaporte Verde: Gestão Ambiental e Competitividade. Rio de Janeiro: Qualitymark, 1996.

MERICO, L. F. K. Proposta metodológica de avaliação do desenvolvimento econômico na região do Vale do Itajaí (SC) através de indicadores ambientais. Revista Dynamis, v. 5, n.19, p. 59-67, 1997.

MINISTÉRIO DO MEIO AMBIENTE, DOS RECURSOS HÍDRICOS E DA AMAZÔNIA LEGAL. Agenda 21: o caso do Brasil - perguntas e respostas. Políticas, instrumentos e normas ambientais. Brasília: MMA, 1998.
MITCHELL, G. Problems and Fundamentals of sustainable development indicators. Disponível em: http://www.lec.leeds.ac.uk/people/gordon. html. Acesso em 31 out. 2006.

PACHECO, J. M. J. A inserção de Indicadores de Medição do Desempenho para o Sistema de Gestão Ambiental. 2001. 129 f. Dissertação - Engenharia de Produção e Sistemas, Universidade Federal de Santa Catarina, Florianópolis, 2001.

SPANGENBERG, J. H., BONNIOT, O. Sustainability Indicators - A Compass on the Road Towards Sustainability. Wuppertal Institute for Climate, Environment, Energy, Wuppertal Paper No 81, February 1998.

TACHIZAWA T. Gestão Ambiental e responsabilidade social corporativa. São Paulo: Atlas, 2005.

TOCCHETTO, M. R. L.; TOCCHETTO A. L. Indicadores de desempenho ambiental para empresas com atividade galvânica. Anais do I Congresso Acadêmico sobre o Meio Ambiente e Desenvolvimento Sustentável do Rio de Janeiro, FGV, Rio de Janeiro, 2004.

TYTECA, D.; VAN DEN BERGHE, S.; CALLENS, I. et al. Indicators of Environmental Performance and Sustainable Development. Louvain-LaNeuve: Université Catholique de Louvain, Working Paper, 1997.

VALLE, C. E. Qualidade Ambiental - O desafio de ser competitivo protegendo o meio ambiente. São Paulo: Pioneira, 137 p., 1995.

VATIMBELLA, A. Le capitalisme vert. Coll. Alternatives Économiques. Paris: Syros, 1992.

\section{SOBRE OS AUTORES}

\section{Lucila Maria de Souza Campos}

Programa de Pós-Graduação em Administração e Turismo (PPGAT/UNIVALI)

End.: Servidão Canarinho, 317 - Rio Tavares - Florianópolis/SC - CEP 88.048-440

E-mails: lucila@univali.br e lucila.campos@terra.com.br

\section{Daiane Aparecida de Melo}

Programa de Pós-Graduação em Administração e Turismo (PPGAT/UNIVALI) e SENAI Jaraguá do Sul End.: Rua Patrício Antonio Teixeira, 317 - Jd. Carandaí - Biguaçu/SC - CEP 88.160-000

E-mail: dai@senai-sc.ind.br 